\title{
Efficacy of spinal extension exercise program versus muscle energy technique in treatment of chronic mechanical low back pain
}

\author{
E. Fahmy ${ }^{1}$, H. Shaker ${ }^{2}$, W. Ragab², H. Helmy ${ }^{1 *}$ and M. Gaber ${ }^{2}$
}

\begin{abstract}
Background: Mechanical low back pain (MLBP) is a major cause of illness and disability, especially in people of working age. People with chronic low back pain often experience anger, fear, anxiety, decrease in physical ability, and inadequacy of role fulfillment.
\end{abstract}

Objective: This study aimed to compare the efficacy of extension exercise program versus muscle energy technique in treating patients with chronic mechanical low back pain.

Subjects and methods: Forty patients complaining of chronic mechanical low back pain participated in the study. Patients were randomly allocated into two equal groups: group A which received spinal extension exercise program and group B which received muscle energy technique. Treatment sessions were given three times per week for four successive weeks. Patients were assessed before and after treatment using visual analogue scale (VAS), Oswestry Disability Index (ODI), and digital goniometer to assess pain intensity, functional disability, and range of motion (ROM) of lumbar spine respectively.

Results: There was significant decrease in the scores of pain and functional disability in both groups post-treatment especially in group B. There was significant increase in lumbar range of motion in both groups post-treatment, especially in group A.

Conclusion: Extension exercise program had better effect on improving lumbar range of motion, whereas muscle energy technique was better in decreasing pain and functional disability in patients with chronic mechanical low back pain.

Keywords: Chronic mechanical low back pain, Muscle energy technique, Spinal extension program

\section{Introduction}

Mechanical back pain could be a general definition that refers to any sort of back pain caused by inserting abnormal stress and strain on muscles of the backbone. Typically, mechanical pain results from dangerous habits, like poor posture, poorly designed seating, and incorrect bending and lifting motions [1]. Mechanical low back pain (LBP) remains a vital health drawback and a serious explanation for incapacity within the operating age, and in most of the cases, there is no clear underlying pathology [2]. There are several factors inflicting

\footnotetext{
* Correspondence: drhananelgendy76@gmail.com

'Department of Neurology, Cairo University, Cairo, Egypt

Full list of author information is available at the end of the article
}

mechanical low back pain, like excessive masses to normal spinal structures. The loads transmitted to the spine are affected by posture, body mechanics, trunk strength, and also flexibility in addition to strength of the muscles of the pelvic arch and lower extremities [1]. McKenzie extension exercise could be a treatment of selection of LBP that specializes in sustained posture or continual movement, which will cause marvelous improvement in pain intensity [3]. Studies have shown that the goals of McKenzie program have resulted in decreasing and rising pain, improvement of body part quality, and return to normal functioning in daily activities $[4,5]$. Muscle energy technique is an associate degree of osteopathic manipulation methodology. The muscles of patients 
were used, on request, to type a singular controlled position, in a very specific direction, and against a distinctly executed therapist-applied counterforce. Muscle energy technique could be a post-isometric relaxation, because it reduces the tone of a muscle or cluster of muscle after a brief period following an isometric contraction. The result of post-isometric relaxation is mediated by receptive input from Golgi connective tissue organ (GTO) that has associate degree repressive result on the antagonist muscles mediated by the muscle spindle receptive [6]. This study was designed to check the effectualness of extension exercise program versus muscle energy technique in rising pain, practical incapacity, and lumbar spine quality in patients with chronic mechanical low back pain.

\section{Subjects and methods}

This is a case-control study conducted on 40 patients with chronic mechanical low back pain with no history of medical treatment. The study was approved by the ethical committee of the Department of Physical Therapy for Neuromuscular Disorder and its Surgery (no. P.T.REC/ 012/002258). Aim and procedures were explained to all patients, and informed written consents were taken from the patients prior to participation.

Patients were selected from neurology, orthopedic, and rheumatology outpatient clinics of Ras-elteen General Hospital in the period from June 2017 to December 2017.

Inclusion criteria were patients (from both sexes) suffering from chronic mechanical low back pain for at least 3 months, body mass index (BMI) ranged from 25 to $33 \mathrm{~kg} / \mathrm{m}^{2}$, normal plain X-ray, and CT or MRI of the lumbar spine.

Exclusion criteria were patients with lumbar spine diseases (for example, disc prolapse or spondylolisthesis), abnormal neurological sign in lower extremities, radicular pain in the lower limb, previous back surgery, hip arthrosis, congenital musculoskeletal deformity, female patients with pelvic lesions, and pregnant females.

Patients were randomly assigned into two equal groups: group A which included 20 patients who received spinal extension exercise program and group B which included 20 patients who received muscle energy technique.

Visual analogue scale (VAS) was used to assess pain through a line of $10 \mathrm{~cm}$ divided from 0 to 10 , where 0 refers to no pain and 10 refers to the worst pain [7]. Oswestry Disability Index (ODI) is a valid and reliable tool for measuring the functional disability in patients with low back pain. It consists of 10 questions, each question includes 6 choices, and the patient selected the best 1 which described his disability. The maximum score is 50 [7]. Digital goniometer is an electromechanical device or system for measuring a selected angle of range of motion (ROM), origin the USA, Model B000N549S6.

In this study, the digital goniometer was used to obtain the range of lumbar flexion, extension, and lateral flexion (bending) towards right and left.

Group A patients received McKenzie extension exercise program which included active back extension from prone, upper back strengthening, push-up, and back extension from standing.

Group B patients received muscle energy technique which involved isometric contraction of the agonist muscle for $10 \mathrm{~s}$. This contraction started just short of the restriction range. After that, the patient was asked to relax for 2-3 s, and then, the examiner stretched the contracted muscle in the opposite direction for $10 \mathrm{~s}$. This was repeated three repetitions for each muscle bilaterally [6]. This technique was applied to the gastrocnemius, soleus, thigh adductors, rectus femoris, iliopsoas, hamstring, tensor fascia lata, and lower back muscles.

Both groups received 12 sessions of treatment, 3 times per week for successive 4 weeks. Patients were assessed before and after treatment for the outcome measures of pain, functional disability, and ROM of lumbar spine.

\section{Statistical analysis}

The collected data were coded, tabulated, and statistically analyzed using IBM SPSS Statistics (Statistical Package for Social Sciences) software version 22.0, IBM Corp., Chicago, USA, 2013. Descriptive statistical analysis was performed for all pre- and post-treatment variables, and all data are expressed as mean and standard deviation. The box and whisker plots of the tested variable were done to detect outliers. Normality test of data using Shapiro-Wilk test was used that reflects the data was normally distributed for all dependent variables. Accordingly, $2 \times 2$ mixed design MANOVA was used to compare the tested variables of interest at different tested groups and measuring periods, with the initial alpha level set at 0.05 . Prior to the final analysis, data were screened for normality assumption, homogeneity of variance, and presence of extreme scores. This exploration was done as a pre-requisite for parametric calculations of the analysis of difference. Descriptive analysis using histograms with the normal distribution curve showed that ROM of shoulder abduction and flexion, Wolf Motor Function Test (WFMT) (function ability score and time, grip strength), trunk impairment (static and dynamic sitting balance score and coordination) score were normally distributed and not violating the parametric assumption for the measured dependent variable.

\section{Results}

General characteristics of patients in both groups are illustrated in Table 1. Both groups were matched as regards age, gender, weight, height, and BMI. 
Table 1 General characteristics of both groups

\begin{tabular}{lllll}
\hline & $\begin{array}{l}\text { Group A } \\
(n=20)\end{array}$ & $\begin{array}{l}\text { Group B } \\
(n=20)\end{array}$ & t value & $P$ value \\
\hline Age (yrs.) & $30.10 \pm 6.84$ & $33.20 \pm 6.62$ & -1.457 & 0.153 (NS) \\
Gender & & & & \\
$\quad$ Male [ $(\%)]$ & $12(60.0 \%)$ & $10(50.0 \%)$ & 0.404 & 0.525 (NS) \\
$\quad$ Female [ $(\%)]$ & $8(40.0 \%)$ & $10(50.0 \%)$ & & \\
Weight $(\mathrm{kg})$ & $84.20 \pm 4.97$ & $86.75 \pm 8.98$ & -1.111 & 0.276 (NS) \\
Height $(\mathrm{cm})$ & $172.10 \pm 8.80$ & $168.15 \pm 5.08$ & 1.738 & 0.092 (NS) \\
BMl $\left(\mathrm{kg} / \mathrm{m}^{2}\right)$ & $28.62 \pm 3.29$ & $30.80 \pm 4.21$ & -1.823 & 0.076 (NS) \\
\hline
\end{tabular}

$\%$ percentage, $\mathrm{kg}$ kilograms, $\mathrm{cm}$ centimeters, $\mathrm{NS}$ not significant

Pain scores were significantly decreased in both groups post-treatment $(p=0.001)$. The percentage of decrease in VAS scores was significantly higher in group B than group A (72.97 versus $49.29 \%)$. Moreover, there was a significant difference between both groups regarding pain scores post-treatment, being significantly lower in group B ( $p=0.001)$, Table 2 .

ODI scores showed a significant decrease in both groups post-treatment $(p=0.001)$ indicating a decrease of functional disability. The percentage of decrease in Oswestry scores was higher in group B than group A (6.87\% versus $4.82 \%)$. However, no significant difference was detected between both groups regarding ODI scores pre- or post-treatment ( $p=0.685,0.799$ respectively), Table 3.

The range of flexion of the lumbar spine was significantly increased in both groups post-treatment ( $p=$ 0.001). The percentage of change in flexion was significantly higher in group A than group B (19.8 versus $16.67 \%)$. However, there was a significant difference between both groups regarding the range of lumbar flexion pre- or post-treatment ( $p=0.931,0.700$ respectively), Table 4.

The range of extension of the lumbar spine was significantly increased in both groups post-treatment ( $p=$ 0.001). The percentage of change in extension was significantly higher in group A than group B (33.38 versus 29.61\%). However, no significant difference was detected

Table 2 Comparison of mean scores of VAS within and between both groups

\begin{tabular}{lllll}
\hline & $\begin{array}{l}\text { Group A } \\
(n=20)\end{array}$ & $\begin{array}{l}\text { Group B } \\
(n=20)\end{array}$ & $t$ value & $P$ value \\
\hline Pre-treatment & $7.00 \pm 1.45$ & $7.40 \pm 1.27$ & -0.927 & 0.360 (NS) \\
Post-treatment & $3.55 \pm 0.83$ & $2.00 \pm 0.86$ & 5.820 & $0.001(\mathrm{~S})$ \\
Mean difference & 3.45 & 5.40 & & \\
\% change & 49.29 & 72.97 & & \\
$t$ value & 14.693 & 23.081 & & \\
$p$ value & $0.001(\mathrm{~S})$ & $0.001(\mathrm{~S})$ & & \\
\hline
\end{tabular}

NS not significant, $S$ significant, VAS visual analogue scale
Table 3 Comparison between mean scores of Oswestry Disability Index within and between both groups

\begin{tabular}{lllll}
\hline & $\begin{array}{l}\text { Group A } \\
(n=20)\end{array}$ & $\begin{array}{l}\text { Group B } \\
(n=20)\end{array}$ & Z value & $P$ value \\
\hline Pre-treatment & $52.95 \pm 6.33$ & $52.22 \pm 14.45$ & -0.406 & 0.685 (NS) \\
Post-treatment & $50.40 \pm 6.17$ & $48.63 \pm 14.29$ & -0.298 & 0.766 (NS) \\
Mean difference & 2.55 & 3.59 & & \\
\% change & 4.82 & 6.87 & & \\
$Z$ value & -3.925 & -3.926 & & \\
$p$ value & $0.001(\mathrm{~S})$ & $0.001(\mathrm{~S})$ & & \\
\hline
\end{tabular}

NS not significant, $S$ significant

between both groups regarding the range of lumbar extension pre- or post-treatment $(p=0.191,0.170$ respectively), Table 5.

The range of right side bending was significantly increased in both groups post-treatment $(p=0.001)$. The percentage of change was significantly higher in group A than in group B (39.52 versus $36.80 \%)$. However, no significant difference was detected between both groups regarding right side bending pre- or post-treatment $(p=$ 0.711, 0.387 respectively), Table 6 .

The range of left side bending was significantly increased in both groups post-treatment $(p=0.001)$. The percentage of change was significantly higher in group A than group B (50.35 versus 40.13\%). However, no significant difference was detected between both groups regarding left side bending pre- or post-treatment ( $p=$ $0.351,0.541$ respectively), Table 7 .

\section{Discussion}

Physical activity could be a viable therapeutic modality for chronic pain conditions that results in helpful effects on pain, sleep, psychological feature, and physical functions. International pointers for managing pain in older adults suggest conservative, non-medicinal management, together with mostly exercise-based therapies [8]. The present study disclosed important decrease in pain scores in each team post-treatment particularly in group $B$ who received muscle energy technique (MET). This

Table 4 Comparison of mean values of flexion of lumbar spine within and between both groups

\begin{tabular}{lllll}
\hline & $\begin{array}{l}\text { Group A } \\
(n=20)\end{array}$ & $\begin{array}{l}\text { Group B } \\
(n=20)\end{array}$ & $t$ value & $P$ value \\
\hline Pre-treatment & $51.00 \pm 11.77$ & $51.30 \pm 10.01$ & -0.087 & 0.931 (NS) \\
Post-treatment & $61.10 \pm 11.92$ & $59.85 \pm 8.11$ & 0.388 & 0.700 (NS) \\
Mean difference & 10.10 & 8.55 & & \\
\% change & 19.80 & 16.67 & & \\
t value & -14.522 & -7.616 & & \\
$p$ value & $0.001(\mathrm{~S})$ & $0.001(\mathrm{~S})$ & & \\
\hline
\end{tabular}

NS not significant, $S$ significant 
Table 5 Comparison of mean values of extension of lumber spine within and between both groups

\begin{tabular}{lllll}
\hline & $\begin{array}{l}\text { Group A } \\
(n=20)\end{array}$ & $\begin{array}{l}\text { Group B } \\
(n=20)\end{array}$ & $t$ value & $P$ value \\
\hline Pre-treatment & $39.35 \pm 15.69$ & $33.70 \pm 10.72$ & 1.330 & 0.191 (NS) \\
Post-treatment & $51.00 \pm 14.76$ & $44.95 \pm 12.53$ & 1.397 & 0.170 (NS) \\
Mean difference & 11.65 & 11.25 & & \\
\% change & 33.38 & 29.61 & & \\
$t$ value & -11.766 & -6.999 & & \\
$p$ value & $0.001(\mathrm{~S})$ & $0.001(\mathrm{~S})$ & & \\
\hline
\end{tabular}

NS not significant, $S$ significant

came in agreement with Wilson et al. [9] and Mindy and colleagues [10] who expressed that the patient has larger profit by using MET than using fiber bundle reeducation and resistance exercises to scale back low back pain and improve practical level in subjects with repeated low back pain. Priyanka and colleagues [11] additionally found MET possesses value-added helpful result for decreasing pain and incapacity and improve the performance of patients with chronic nonspecific low back pain alongside supervised exercises, hot pack, and transcutaneous electrical nerve stimulation (TENS). On the contrary, Bindra and colleagues [12] reported no significance between MET and other therapies regarding pain and functional status.

The physiological mechanisms underlying the therapeutic effects of MET may involve a variety of neurological and biomechanical mechanisms, including hypoalgesia, altered proprioception, increase in stretch tolerance, motor programming and control, and changes in tissue fluid [13].

On the other hand, Murtezani and colleagues [14] compared McKenzie (MK) exercises with electrophysical agents (heat, ultrasound, interferential current) and found greater reduction of VAS scores in MK exercise group than the electrophsiological agents (EPAs) group. Better results in reducing pain intensity were also obtained with MK method compared with resistance training (Udermann and colleagues [15]) and supervised

Table 6 Comparison of mean values of right side bending within and between both groups

\begin{tabular}{lllll}
\hline & $\begin{array}{l}\text { Group A } \\
(n=20)\end{array}$ & $\begin{array}{l}\text { Group B } \\
(n=20)\end{array}$ & $t$ value & $P$ value \\
\hline Pre-treatment & $29.10 \pm 6.16$ & $28.40 \pm 5.71$ & 0.373 & 0.711 (NS) \\
Post-treatment & $40.60 \pm 7.49$ & $38.85 \pm 4.85$ & 0.878 & 0.387 (NS) \\
Mean difference & 11.50 & 10.45 & & \\
$\%$ change & 39.52 & 36.80 & & \\
$t$ value & -13.373 & -17.281 & & \\
$p$ value & $0.001(\mathrm{~S})$ & $0.001(\mathrm{~S})$ & & \\
\hline
\end{tabular}

NS not significant, $S$ significant
Table 7 Comparison of mean value of left side bending within and between groups

\begin{tabular}{lllll}
\hline & $\begin{array}{l}\text { Group A } \\
(n=20)\end{array}$ & $\begin{array}{l}\text { Group B } \\
(n=20)\end{array}$ & $t$ value & $P$ value \\
\hline Pre-treatment & $28.20 \pm 3.50$ & $29.65 \pm 5.88$ & -0.948 & 0.351 (NS) \\
Post-treatment & $42.40 \pm 4.08$ & $41.55 \pm 4.62$ & 0.617 & 0.541 (NS) \\
Mean difference & 14.20 & 11.90 & & \\
\% change & 50.35 & 40.13 & & \\
$t$ value & -21.218 & -14.796 & & \\
$p$ value & $0.001(\mathrm{~S})$ & $0.001(\mathrm{~S})$ & & \\
\hline
\end{tabular}

$\overline{N S}$ not significant, $S$ significant

exercise (Sakai and colleagues [16]). Pain reduction after treatment by MK might be attributed to posture correction and maintenance of correction which is an important aspect of MK exercise [17].

In this study, there was an important reduction of ODI scores in each team post-treatment, particularly in the group B who received MET. This came in accordance with Udermann and colleagues [15] who showed that McKenzie coaching improved pain, disability, and psychosocial variables in patients with chronic low back pain. Machado and colleagues [18] additionally showed that there is a discount in pain and incapacity thanks to MK technique for a minimum of 1 week compared with the passive treatment strategies. Moreover, Garcia and colleagues [19] showed that exploiting MK technique helps to improve the practical ability of chronic low back pain cases to hold out daily activities while not feeling pain which could flow from to the effectivity of control exercises for patients. This study disclosed important post-treatment increase of body part in flexion, extension, and right and left aspect bending in each team particularly in group A who received MK exercises. These findings are in agreement with Hosseinifar and colleagues [20] who showed that MK coaching could be a favorable technique for reducing pain and increasing various motions of body part flexion in patients with chronic low back pain. Also, Kilpikoski and colleagues [21] found that MK educational program ends up in recovery of low back pain symptoms like pain within the short-run. Moreover, this coaching is made to mobilize the spine and to strengthen the body part muscles. An attainable rationalization is that MK extension exercise program focuses on sustained posture or continual movement that might cut back pain. It is based mostly chiefly on characterizing the directional preference for spinal movement and the idea for prescription of exercises. It incorporates continuous various movements, and also, the direction for exercise depends upon the patients' response to those repeated movements. Posture correction and maintenance of this correction are the vital aspects of MK exercises [17]. On the opposite hand, 
Mesquita and colleagues [22] reported an important increase in body part flexion and extension within the MET cluster compared to controls. In distinction, Patil and colleagues [23] determined that MET and also the management intervention were equally effective in increasing aspect flexion, spinal flexion, and spinal extension. Ellythy and colleagues [24] additionally reported no distinction in body part flexion and extension between MET and also the management cluster. In conclusion, the authors suggest adding MET to spinal extension exercise programs to extend their effectivity in decreasing pain and incapacity and improve the quality of the performance of patients with chronic low back pain.

\section{Limitations}

This study is limited because we should compare between acute and chronic cases. Also, we should have larger number of cases.

\section{Abbreviations}

ANOVA: One-way analysis variance; BMI: Body mass index; GTO: Golgi tendon organ; MLBP: Mechanical low back pain; ROM: Range of motion; SPSS: Statistical Program for Social Science; VAS: Visual analogue scale

\section{Acknowledgements}

The authors acknowledge the subjects for their participation and cooperation in the study.

\section{Authors' contributions}

EF and HS contributed to the research idea and conception. WR, HH, and MG contributed to the data acquisition, data analysis, interpretation, and manuscript writing and review. All authors read and approved the final manuscript.

\section{Funding}

This research received no specific grant from any funding agency in the commercial or not-for-profit sectors.

\section{Availability of data and materials}

The datasets generated and/or analyzed during the current study are not publicly available due to current Cairo University regulations and Egyptian legislation but are available from the corresponding author on reasonable request and after institutional approval.

\section{Ethics approval and consent to participate}

The aim and procedures of the study were explained to every participant, and an informed written consent was obtained from all the patients before being enrolled in the study. The study was approved by the ethical committee of the Department of Physical Therapy for Neuromuscular Disorder and Its Surgery on May 2017 (No P.T.REC/012/002258), Faculty of Physical Therapy, Cairo University.

\section{Consent for publication}

Not applicable.

\section{Competing interests}

The authors declare that they have no competing interests.

\section{Author details}

'Department of Neurology, Cairo University, Cairo, Egypt. ²Department of Physical Therapy of Neuromuscular Disorders and Its Surgery, Faculty of Physical Therapy, Cairo University, Cairo, Egypt.
Received: 9 April 2019 Accepted: 11 October 2019

Published online: 02 December 2019

\section{References}

1. Rucker K, Cole A, Wenistein S. Low back pain, A symptom based approach to diagnosis and treatment. Bulterworth Heinemnn, Boston, USA; 2001. p. $5-7$.

2. Lötters F, Burdorf A, Kuiper J, Miedema H. Model for the work-relatedness of low-back pain. Scand J Work Environ Health. 2003;29(6):431-40.

3. Hosseinifar M, Akbari M, Behtash H, Amiri M, Sarrafzadeh J. The effects of stabilization and McKenzie exercises on transverse abdominis and multifidus muscle thickness, pain, and disability: a randomized controlled trial in nonspecific chronic low back pain. J Phys Ther Sci. 2013;25(12):1541-5

4. Johnson O.E. Therapeutic exercises in the management of non-specific low back pain. 2012, ISBN: 978-953-51-0599-2

5. McKenzie RA, May S. The lumbar spine: mechanical diagnosis and therapy. 2nd ed. Waikanae: Spinal Publications; 2003.

6. Chaitow L. Muscle energy techniques. 3rd ed. Edinburgh: Churchill Livingstone; 2006

7. Jensen MP, Chen C, Brugger AM. Interpretation of visual analog scale ratings and change scores: a reanalysis of two clinical trials of postoperative pain. J Pain. 2003;4(7):407-14

8. Wand BM, Parkitny L, O'Connell NE, Luomajoki H, McAuley JH, Thacker M, Moseley GL. Cortical changes in chronic low back pain: current state of the art and implications for clinical practice. Manual Ther. 2001;16:15-20.

9. Wilson E, Payton O, Donegan-Shoaf L, Dec K. Muscle energy technique in patients with acute low back pain: a pilot clinical trial. J Orthop Sports Phys Ther. 2003;33(9):502-12.

10. Mindy C, Nadine F, Chris W. Randomized controlled trial of specific spinal stabilization exercises and conventional physiotherapy for recurrent low back pain. Spine. 2006;31(9):E670-81.

11. Dhargalkar P, Kulkarni A, Ghodey S. Added effect of muscle energy technique for improving functional ability in patients with chronic nonspecific low back pain. Int J Physiother Res. 2017;5(3):2082-7.

12. Bindra S, Kumar $M$, Singh $P$, Singh J. A study on the efficacy of muscle energy technique as compared to conventional therapy in chronic low back pain due to sacroiliac joint dysfynction. Indian J Physiother Occup Ther. 2012;6(1):200-33.

13. Fryer $G$, Fossum $C$. Therapeutic mechanisms underlying muscle energy approaches. In: Fernandez-de-las-Penas C, Lars A-N, Gerwin RD, editors. Tension- Type and Cervicogenic Headache: Pathophysiology, Diagnosis, and Management. Sudbury: Jones and Bartlett Publishers; 2010.

14. Murtezani A, Govori V, Meka VS, Ibraimi Z, Rrecaj S, Gashi S. A comparison of McKenzie therapy with electrophysical agents for the treatment of work related low back pain: a randomized controlled trial. J Back Musculoskelet Rehabil. 2015;28(2):247-53.

15. Udermann BE, Mayer JM, Donelson RG, Graves JE, Murray SR. Combining lumbar extension training with McKenzie therapy: effects on pain, disability, and psychosocial functioning in chronic low back pain patients. Gundersen Lutheran Med J. 2004;3:7-12.

16. Sakai $Y$, Matsuyama $Y$, Nakamura $H$, Katayama $Y$, Imagama $S$, Ito $Z$, et al. The effect of muscle relaxant on the paraspinal muscle blood flow: a randomized controlled trial in patients with chronic low back pain. Spine. 2008;33(6):581-7.

17. Clare HA, Adams R, Maher CG. A systematic review of efficacy of McKenzie therapy for spinal pain. Aust J Physiother. 2004;50(4):209-16.

18. Machado LA, Maher CG, Herbert RD, Clare H, McAuley JH. The effectiveness of the McKenzie method in addition to first-line care for acute low back pain: a randomized controlled trial. BMC Med. 2010;8:10.

19. Garcia JB, Hernandez-Castro JJ, Nunez RG, Pazos MA, Aguirre JO, Jreige A et al. Prevalence of low back pain in Latin America: a systematic literature review. Pain Physi. 2014;17(5):379-91.

20. Hosseinifar M, Akbari A, Shahrakinasab A. The effects of McKenzie and lumbar stabilization exercises on the improvement of function and pain in patients with chronic low back pain: a randomized controlled trial. $J$ Shahrekord Univ Med Sci J. 2009;11(1):1-9.

21. Kilpikoski S. The McKenzie method in assessing, classifying and treating non-specific low back pain in adults with special reference to the centralization phenomenon. Jyväskylä: University of Jyväskylä; 2010. 
22. Mesquita R. Comparison of trunk stabilization exercises and muscle energy technique in recurrent low back pain. A randomized clinical trial. Belgaum: KLE University; 2012.

23. Patil P, Chandu B, Metgud S, Khatri S. Effectiveness of muscle energy on quadratus lumborum in acute low back pain - randomized controlled trial. Indian J Physiother Occup Ther. 2010;4(1):54-8.

24. Ellythy MA. Efficacy of muscle energy technique versus strain counter on low back dysfunction. Bull Fac P Th Cairo Univ. 2012;17(2).

\section{Publisher's Note}

Springer Nature remains neutral with regard to jurisdictional claims in published maps and institutional affiliations.

Submit your manuscript to a SpringerOpen ${ }^{\circ}$ journal and benefit from:

- Convenient online submission

- Rigorous peer review

- Open access: articles freely available online

High visibility within the field

- Retaining the copyright to your article

Submit your next manuscript at $\boldsymbol{\nabla}$ springeropen.com 